\title{
Analyzing the learning style and study habit of students in the faculty of nursing of Al Jabal Al Gharbi University, Gharyan, Libya
}

\author{
June II A. Kiblasan*1, Badridden F.A. Abufayed ${ }^{1}$, Aisha A. Sehari ${ }^{2}$, Florbeth U. Madamba ${ }^{1}$, Kaltoom H. Mhanna ${ }^{1}$ \\ ${ }^{1}$ Faculty of nursing, Al Jabal Al Gharbi University, Gharyan, Libya \\ ${ }^{2}$ Faculty of Medicine, University of Tripoli, Tripoli, Libya
}

Received: February 11, 2016

DOI: $10.5430 /$ cns.v4n2p48

\author{
Accepted: March 31, 2016 \\ Online Published: April 20, 2016 \\ URL: http://dx.doi.org/10.5430/cns.v4n2p48
}

\begin{abstract}
Through learning, everyone becomes educated but learners should have a style to learn and possess a habit that match how they study. These two variables are vital as guide for educators or mentors to come up with such methodology or strategy in promoting quality and effective teaching-learning environment. With this, it is the purpose of this study to investigate the learning style and study habit of students in the Faculty of Nursing, Al Jabal Al Gharbi University, Gharyan, Libya according to their gender, year level and age group. A mixed methods of research was used and the data gathering tool used to assess variables consisted of the Visual, Auditory and Kinaesthetic (VAK) Learning Style Inventory (LSI) and the Study Habit Inventory utilizing the study attitude inventory (SAI) with four scales known as Motivation, Study Method, Exam Technique and Lack of Distraction. A descriptive design was employed to determine the learning style and study habit of Bachelor of Science in nursing (BSN) students. Generally, BSN students found to be visual learners and have the motivation as the most scaled study habit. Furthermore, differences on learning style and study habit according to demographic profile vary. Indeed, There is a strong relationship between the learning style and study habit among BSN students of Al Jabal Al Gharbi University, Gharyan, Libya.
\end{abstract}

Key Words: Learning style, Study habit, Nursing education, Bachelor of Science in nursing students

\section{INTRODUCTION}

Learning is a need of an individual to be educated at which, it is a requirement for learners to possess a study habit for them to learn as learning is the only key to eradicate illiteracy no matter what level it is. Through education, learners can be developed so it is a must for educators to upgrade teaching effectiveness to promote quality teaching-learning environment. All tertiary or higher education institution and technical vocational school aimed to improve learning capability then guide students on matched study habit to promote learning. This is the reason why many efforts by school administrators have been done to improve the retention of their students through continuous academic advising, orientations, facility improvements, mentoring, and modifications on curriculum and pedagogy to ensure that the student's learning style and study habit are explored without reducing their self-determination. But some instances are beyond the control of an educational institution and it is within students themselves if they are interested to learn. Afful-Broni $\&$ Mawusi $^{[1]}$ stated in their study that "students perceive and learn in different ways likewise they study in different ways" and they "may have different learning styles. Thus,

*Correspondence: June II A. Kiblasan; Email: jiiak0321@yahoo.com; Address: Faculty of Nursing, Al Jabal Al gharbi University, Gharyan, Libya. 
the process of learning involves many factors, such as selfconfidence, intelligence, aptitude, motivation and learning styles. Furthermore, another significant factor is learners' study habits. The importance of study habits can be gauged from the findings of a number of studies. ${ }^{[2-8]}$

Being a human, it has been recognized that we are not totally the same in terms of observations and interactions. Senses were applied differently and opinions or ideas are shared based on individual's thinking and feeling. Preferences and choices in life are also completely different. It is therefore not inconceivable to think that we can learn differently as well. ${ }^{[9]}$ Each individual has a special way of grasping a particular concept or situation. That over the years, there has been several different ways of defining a learning style. ${ }^{[10]}$ Smith \& Dalton ${ }^{[11]}$ defined learning style as a unique and habitual behaviour of acquiring knowledge and skills through everyday study or experience. While Felder \& Silverman ${ }^{[12]}$ described it as the way in which persons receive and process information. Moreover, Kolb ${ }^{[13]}$ had his own opinion as to what a learning style is. He defined it as the process of creating knowledge through the transformation of experience. The general theme of these definitions suggests that learning style encompasses the acquiring, processing and recalling information by an individual through particular experiences. Learning style refers to the way in which an individual concentrates on processes, internalizes, and retains new and difficult information. ${ }^{[14]}$ When students are aware of their own styles they are more likely to take initiatives in their own learning process and make adjustments to learn in a way that is suited to their preferences. Students may use knowledge of their own styles to help them do homework, solve problems, and better sort through information. ${ }^{[15,16]}$ Indeed, the concept of learning style describes individual differences in learning based on the learner's preference for employing different phases of the learning cycle. ${ }^{[17]}$

On the other hand, the learner's dictionary defined study as a "mental effort to obtain knowledge". This means that studying is an art of learning which helps the individual not only to acquire knowledge but also the skill and the habit to study. While habit is a second nature; it is a routine of an individual in every condition that is something is simply done on a scheduled, regular, planned basis to one's life with no reservations, no excuses, and no expectations. In relation to learning, a student should possess a habit that is beneficial to self in the long run of their studies. A habit that may involve their attitude, skills or behaviour in studying in order for them to succeed in the field of education they would like to be which we can termed as study habit. Good defined study habits as "the students way of study whether systematic, efficient, or inefficient etc". ${ }^{[5]}$ A study habit is buying

Published by Sciedu Press out a dedicated scheduled and uninterrupted time to apply oneself to the task of learning. Without it, one does not grow and becomes self-limited in life. It is also a pattern of activity through repetition, has been learned to the point that it has become automatic and can be carried on with a minimum of conscious effect to achieve maximum success in his school work. Study habit, therefore, refers to learning which leads to the achievement of a learner's goal, through a prescribed pattern of a study behaviour. Study habit plays a major role to the learning style of an individual. Effective study habits help students to achieve good results. ${ }^{[18]}$ It also refers to the tendency of a student to use his/her uninterrupted attention to acquire knowledge via systematic routines. ${ }^{[8,19]}$ But there are scenarios that learners realize on the latter that their study habit do not match with the style they need to learn that made them identify particular study habit according to their learning style and possibly improve academically. Hoeffner ${ }^{[20]}$ sought to determine whether there was an improvement in grades after the adjustment of their study habits once their learning styles were identified. This study was inconclusive since not all of the students modified their study habits. However, those who did modify their study habits in relation with their learning styles agreed that the change was quite beneficial. Fielden ${ }^{[21]}$ stated that good study habits help the student in critical reflection in skills outcomes such as selecting, analyzing, critiquing, and synthesizing. Nneji ${ }^{[22]}$ stated that study habits are learning tendencies that enable students work privately. Azikiwe ${ }^{[4]}$ described study habits as the way and manner a student plans his or her private reading outside lecture hours in order to master a particular subject or topic. Study habits help students master their areas of specialization. Moreover, study habit is the pattern of activities adopted by a student in the pursuit of their studies that serves as the vehicle of learning. It is the degree to which the student engages in regular undertakings relevant to learning that is characterized by an appropriate venue for studying. Study attitudes, on the other hand, refers to a student's positive attitude toward the specific act of studying and the student's acceptance and approval of the broader goals of college education. ${ }^{[8]}$

Understanding one's learning style(s) is imperative but being able to master one's study habits and skills could tremendously reduce the issues of under achievement that is still on the rise among students. ${ }^{[23,24]}$ At this point, it has been observed that Libyan Bachelor of Science in Nursing (BSN) students' level of achievement are deteriorating to which almost $50 \%$ are not qualified to be promoted to the next level of their studies. Most of the teaching staff are foreigners is one of the reasons. They cannot understand sometimes how Libyan BSN students learn and study. This is maybe because of their culture, educational system and tradition as 
well. In addition, their behaviour and attitude is critical to be understood. The main reason why this study was conducted is to analyze the learning style and study habit of the BSN students. Specifically, this study sought to identify the learning style preference as well as the study habit of the BSN students; to find if there are significant differences on learning style and study habit according to gender, year level and age; and to find out if there is significant relationship between the learning style and study habit of BSN students. The findings will be beneficial to both teaching staff and the students as the result will guide educators to find methodology how do student learn based on their preferred learning style and the study habit they were utilizing.

\section{METHODS}

The study made use of a mixed method at which there was an integration of quantitative and qualitative schemes in the collection and analysis of data. Quantitatively, cross-sectional descriptive design was applied as it allowed the researchers to collect data regarding the opinion of the participants on a particular topic ${ }^{[25]}$ in one time utilizing a data gathering instrument composed of three parts. Firstly, the Demographic information that include the age, gender and year level followed by Learning Style Inventory (LSI) and the study habit inventory known as Study Attitude Inventory (SAI). Moreover, qualitative approach was done through observations by some of the authors during their classes without the knowledge of the students to substantiate the findings. The tool for LSI followed what was proposed ${ }^{[26]}$ that consist of three learning modalities which are: Visual, Auditory and Kinaesthetic (VAK). This was chosen because of their previous report that learning modality strengths can occur independently or in combination though visual or mixed was the most frequent modality strengths. However, it can change over time and become integrated with age and pointed out that learning modality strengths are different from preferences; a person's self-reported modality preference may not correspond to their empirically measured modality strength. ${ }^{[27]}$ Items on LSI data gathering tool was lifted from the work of Academic Success Services. ${ }^{[28]}$ On the other hand, SAI authored by Entwistle et al. ${ }^{[29]}$ was utilized for the study habits of the students. The tool has four scales namely: Motivation, Study Method, Exam Technique and Lack of Distraction. The tool was administered to both male and female students in the Faculty of Nursing Al Jabal Al Gharbi University in all level at different age brackets purposively as sample depends only on the available students in the Faculty of Nursing during the planned schedule for data gathering. Collected data were tallied and subsequently subjected to statistical treatment using the Statistical Package for Social Sciences
Version 20.0 (SPSS) employing $t$-test of Independent Samples and one-way Analysis of Variance (ANOVA) or F-test in comparing the learning style and study habit according to demographic profile. Furthermore, Pearson product-moment correlation coefficient (PPMCC) was applied to test if there is significant relationship between the learning style and study habit of BSN students.

\section{RESULTS}

\subsection{Distribution of respondents according to demo- graphic profile}

The faculty of nursing in Al Jabal Al Gharbi University, Gharyan Libya has total population of 182 students. $87(47.8 \%)$ students are from the first year; second and third year students has the same sample of 37 $(20.33 \%)$ each; and 21 (11.54\%) students in the fourth year. During data gathering, there are 148 BSN students available that covers the $81.32 \%$ of the total population. There are $79(91 \%$ of 87$)$ students in the first year; 34 (92\% of 37) are second year students; $19(68 \%)$ from 34 students belong to the third year level; and 16 (76\% of 21$)$ are the fourth year students. Further, age of the respondents were grouped according to their stage (adolescence and early adulthood) at which the first group is from age 17-19 with total number of 98 students that covers the $64 \%$ of the total sample while $56 \mathrm{BSN}$ students belong to the age group 20-23 that covers the remaining $36 \%$ of the total sample. Lastly, Majority of the BSN students are females with total number of 138 that covers the $90 \%$ of the total accommodated respondents while only $16(10 \%)$ are male students.

\subsection{Learning style and study habit of BSN students}

Generally, BSN students of Al Jabal Al Gharbi University are visual learners with weighted mean of 11.05 while their second preference is kinesthetic (9.95) style of learning. The least preferred learning style is auditory with weighted mean of 8.05. Table 1 presented the learning style preference of BSN students according to year level, age group and gender. As per year level, first year BSN students are kinesthetic learners. Their preference were arranged as kinaestheticvisual-auditory (KVA) based on their weighted means of $1.72,1.58$ and 1.25 while the second, third and fourth year BSN students have the same preference at which they are all visual (4.26, 13.32 and 37.94) learners as the primary, followed by being kinaesthetic learners with weighted means of 34.06, 11.63 and 33.88 respectively and the least preferred is auditory learning style with weighted means of 3.00, 10.05 and 27.13. Furthermore, age group and gender have the same pattern of learning. Most of them are visual (7.65, 7.60, 8.50 and 7.53 ) then kinaesthetic learning style with weighted 
means of $6.79,7.44,7.06$ and 5.00 and the least is the auditory learning style with weighted means of 5.51, 5.72, 6.25 and 7.00 respectively.

Table 1. Learning style of BSN students

\begin{tabular}{lllll}
\hline \multirow{2}{*}{ Demographic Profile } & \multicolumn{3}{c}{ Learning Style } \\
\cline { 3 - 5 } & First & 1.58 & 1.25 & 1.72 \\
\cline { 2 - 5 } Year level & Second & 4.26 & 3.00 & 4.06 \\
& Third & 13.32 & 10.05 & 11.63 \\
& Fourth & 37.94 & 27.13 & 33.88 \\
\multirow{3}{*}{ Age group } & $17-19$ & 7.65 & 5.51 & 6.79 \\
& $20-23$ & 7.60 & 5.72 & 7.44 \\
\multirow{2}{*}{ Gender } & Male & 8.50 & 6.25 & 7.06 \\
& Female & 7.53 & 5.00 & 7.00 \\
\hline
\end{tabular}

On the other hand, this endeavour successfully investigated the study habit of the BSN students. Generally, motivation was the most scaled study habit with weighted mean of 8.11 followed by study method (7.06) then by exam technique with weighted mean of 4.92 while the least is an attitude "lack of distraction" with weighted mean of 4.19. Table 2 revealed what scale of study habit being utilized by the BSN students according to their demographic profile. The authors found out that the study habit of BSN students go on same pattern. However, the means of "exam technique" and "lack of distraction" study habit by third year BSN student has the same weighted means as the third and least scaled. The most scaled is "motivation" with weighted means of 8.00, 8.21, 8.05 and 8.35 for the profile "year level"; 8.07 and 8.08 for the profile "age group"; and both 8.06 for gender. The second scaled study habit is "study method" with weighted means of $6.90,7.26,6.79$ and 7.25 for the year level; 6.93 and 7.34 for the age group; while 6.56 and 7.47 for the respondents' gender. Exam technique was the third scaled study habit with weighted means of 4.75, 5.00, 4.74 and 5.50 as per year level; 4.81 and 4.96 for the age group; while 4.69 and 4.92 are weighted means according to gender. The least scaled study habit is "lack of distraction" with weighted means of $4.38,4.24,3.74,3.75 ; 4.34,4.02 ; 4.5$, and 4.57 respectively.

Table 2. Study habit of BSN students

\begin{tabular}{llllll}
\hline \multirow{2}{*}{ Demographic profile } & \multicolumn{4}{c}{ Study habit } \\
\cline { 3 - 6 } & First & Exam technique & Lack of distraction & Motivation & Study method \\
\hline \multirow{3}{*}{ Year level } & Second & 5.75 & 4.38 & 8.00 & 6.90 \\
& Third & 4.74 & 4.24 & 8.21 & 7.26 \\
& Fourth & 5.50 & 3.74 & 8.05 & 6.79 \\
\multirow{2}{*}{ Age group } & $17-19$ & 4.81 & 3.75 & 8.38 & 7.25 \\
\multirow{2}{*}{ Gender } & $20-23$ & 4.96 & 4.34 & 8.07 & 6.93 \\
& Male & 4.69 & 4.02 & 8.08 & 7.34 \\
\hline
\end{tabular}

\subsection{Differences in learning style and study habits of BSN students}

With the means of each learning style presented in the previous table, it was presumed that there is a significant difference on learning style of BSN students according to year level. To wit, Table 3 presented the statistical formula at which ANOVA or $F$-test was used to validate the said assumption and it was proven that there is a significant differences on learning style preference of BSN students according to year level at $p<.05$ level with $[F(3,8)=74.776, p=.000]$. Moreover, Levene's Test for Equality of Variances results was used to present and verify the significant differences on age group and gender of the respondents. As revealed in the table, age group has $F$-value of 0.011 while the $p$-value is .920. This result confirms that the means of two age groups do not vary too much on learning style preference at which the variability of the two groups is not significantly different,

Published by Sciedu Press same as to that of the respondents' gender with $F$-value of 0.008 while the $p$-value is .933 .

Table 3. Differences in learning style of BSN students

\begin{tabular}{llllll}
\hline \multicolumn{1}{l}{ Demographic profile } & Mean & $\boldsymbol{S D}$ & $\boldsymbol{F}$ & $\boldsymbol{p}$-value \\
\hline \multirow{4}{*}{ Year level } & First & 1.52 & 0.24 & & \\
& Second & 3.77 & 0.68 & & \\
& Third & 11.67 & 1.64 & 74.776 & .000 \\
& Fourth & 32.98 & 5.46 & & \\
Age group & $17-19$ & 6.65 & 1.08 & & \\
& $20-23$ & 6.92 & 1.04 & 0.011 & .920 \\
Gender & Male & 7.27 & 1.14 & & \\
& Female & 6.68 & 1.05 & 0.008 & .933 \\
\hline
\end{tabular}

Furthermore, Table 4 presented differences in study habit of the BSN students. Again same treatment was applied as how authors dealt with the findings on learning style of 
the BSN students. ANOVA or $F$-test was used to validate if there is a significant differences on study habit of BSN students according to year level at $p<.05$ level for the four year levels $[F(3,12)=0.098, p=.960]$. The result reflected that there is no statistically significant difference between the study habit of BSN students according to year level at which the differences between means are likely due to chance and not likely due to what level in nursing curriculum a student enrolled in. Moreover, Levene's Test for Equality of Variances results was used to present and verify the significant differences on age group and gender of the respondents of the BSN study habit. As revealed in the table, age group has $F$-value of 0.177 while the $p$-value is .689 . This result confirms that the means of 2 age groups do not vary too much on study habit scale at which the variability of the two groups is not significantly different. In addition, $t$-test for Equality of Means substantiated the finding that there is no significant difference between the age group of 17-19 $(\mathrm{M}=6.04$, $S D=1.76)$ and age group 20-23 $(\mathrm{M}=6.10, S D=1.92)$ regarding their study habit scale $[t(6)=0.048, p=.963]$. On the other hand, validating significant difference on study habit of male and female BSN students utilized same process with the age group variable. The $F$-value is 0.202 and the $p$-value is .0689. Again, the means of male and female BSN students do not overly varies on learning style preference so the variability is not significantly different. In support, $t$-test for Equality of Means was considered to corroborate the finding. Indeed, there is no significant difference between the male students $(\mathrm{M}=5.95, S D=1.68)$ and female students $(\mathrm{M}=6.26, S D=1.77)$ regarding their study habit $[t(6)=0.248, p=.812]$.

Table 4. Differences in study habits of BSN students

\begin{tabular}{lllllc}
\hline Demographic profile & Mean & $\boldsymbol{S D}$ & $\boldsymbol{F}$ & $\boldsymbol{p}$-value \\
\hline \multirow{4}{*}{ Year level } & First & 5.59 & 1.21 & & \\
& Second & 6.18 & 1.87 & & \\
& Third & 6.03 & 2.15 & & .96 \\
& Fourth & 6.22 & 2.03 & & \\
Age group & $17-19$ & 6.04 & 1.76 & & \\
& $20-23$ & 6.10 & 1.92 & 0.177 & .689 \\
\multirow{5}{*}{ Gender } & Male & 5.95 & 1.68 & & \\
& Female & 6.26 & 1.77 & 0.202 & .669 \\
\hline
\end{tabular}

\subsection{Relationships between the learning style and study habit of BSN students}

In Table 5, we can see how learning style is correlated to study habit of BSN students utilizing the PPMCC test. The statistical derived values that are essential in validation are Pearson's $r$ is $0.267 ; \mathrm{n}=16 ; p=.318$. The correlation between learning style and study habit is significant at the 0.01 level (2-tailed). This means that there is a strong relationship between the learning style and study habit of BSN students in Al Jabal Al Gharbi University in Gharyan, Libya.

Table 5. Relationship of learning style and study habit of BSN students

\begin{tabular}{llll}
\hline & & Learning Style & Study Habit \\
\hline Learning & Pearson Correlation & 1 & 0.267 \\
Style & Sig. (2-tailed) & & 0.318 \\
& $\mathrm{~N}$ & 16 & 16 \\
Study & Pearson Correlation & 0.267 & 1 \\
Habit & Sig. (2-tailed) & 0.318 & \\
& $\mathrm{~N}$ & 16 & 16 \\
\hline
\end{tabular}

\section{Discussion}

It was a belief and speculations of most that learning style and study habit differs from one individual to another. In our daily lives, learning exists; however, people can be learned depending on what they prefer and the habit they will utilize that will lead them successful. Divergences in learning style and the study habit applied in order to be educated are obviously postulated as a result of individual differences. In this study, the authors found out that BSN students most preferred being visual then by kinesthetic and the least is auditory. The findings is similar to the study of Dunn and Dunn, ${ }^{[30]}$ only $20 \%-30 \%$ of school age children appear to be auditory learners, $40 \%$ are visual learners, and 30\%-40\% is tactile/kinesthetic which is in contrary with the study ${ }^{[31]}$ reported that Chinese university students $(\mathrm{N}=90)$ studying in the USA favored Kinesthetic and Tactile styles while Melton $^{[32]}$ found that Chinese (PRC) university students ( $N=331$ ) favored Kinesthetic, Tactile and Individual styles. Moreover, Jones ${ }^{[33]}$ stated that his Chinese (Taiwan) university students $(\mathrm{N}=81)$ favored Kinesthetic and Tactile styles same as Rossi-Le ${ }^{[34]}$ surveyed adult L2 immigrants in the US and they were in favor with Kinesthetic and Tactile styles while Hyland's Japanese learners favored Auditory and Tactile styles, and disfavored Visual and Group styles and also reports that senior students favored kinesthetic styles. ${ }^{[35]}$ The finding is congruent to what was observed with the first year students by the author in Human Anatomy course. The respondents are Libyan students which are using Arabic in terms of speaking and writing most of the time. They usually don't understand the lesson that much because the medium of instruction is in English language. They keep on asking to repeat the lesson until such they found the teacher is pointing the word spoken to them from the Power Point presentation and a supporting photograph or sketch representation be displayed. Though this is the real scenario of teaching-learning environment observed by the authors, it has been observed that students are doing their effort and some improvement were observed as they go forward to the higher level of their 
studies. Their second learning style preference is kinesthetic in which this also has been proven through observation as they can easily understand the lesson if the mentor uses some body language or gesture while explaining. It has been also observed in the higher level students during their clinical exposure that they cannot able to apply immediately what is being taught to them unless it has been put into action. An example is the medication preparation and administration. This concept was taught to them in a lecture - demonstration strategy but there was no return demonstration by the students. They were found scared of doing in the hospital so the mentor still need to do the procedure then guide them. As to the demographic profile of the students, the first year BSN students are kinesthetic learners. Their preference were arranged as KVA while the second, third and fourth year BSN students have the same preference at which they are all visual then by kinaesthetic and auditory learners. With this, it has been observed that there is shifting from being kinesthetic to visual occurred while the student advances to the next level of their studies. And upon looking on the pattern how the first year learn, It seem that lecture demonstration is necessary for them to listen and understand to be followed by an individual or group activity that substantiate their learning through utilization of their psychomotor domain. Maturity was considered by the authors as another reason why there is shifting of learning style that exist as most of BSN students in the first level belongs to the teenage group. Furthermore, BSN students according to age group and gender are visual learners then kinaesthetic and auditory. At this point, it has been observed that either be kinesthetic or visual comes first. This means that BSN students are readers, watchful and pragmatic in terms of learning. The three descriptions were the best word to describe how the BSN students will learn. Our BSN students are Libyan and use Arabic language and writing as their primary means of communication while English language and writings was utilized as the medium of instruction and communication in the faculty and most of the teaching workforces are foreigners. Because of their great interest to learn, they are trying their effort by reading visual aids in the form of sheets (their terminology for the outlined concepts of the course to be discussed in a given duration) and they even demand some pictures or sketches related with the matter.

Furthermore, this endeavour found out that motivation was the most scaled study attitude as their habit in studying followed by study method then by exam technique while the least is "lack of distraction". With this, mentors play a vital role in the schooling of the students for they are the source of motivation for them to study more. It has been observed from the students that they need motivating stimuli such as good lecture notes and visual aids with good presentation. Once motivation exist, interest to study comes next which obviously seen with the BSN student for their second scaled attitude as their study habit. Moreover, students always approach their mentors if there is a quiz or an activity to evaluate their extent of understanding after discussion of each topic in a course or the next meeting after the lesson that motivates them to study for they considered the exam technique as their third scaled study habit. Lack of distraction was the least and it goes with the real scenario in the faculty because students were observed that they keep on walking along the corridor while trying to put into words what they are studying from their lessons during examinations that create sounds leading to noisy environment. The authors also found out that the study habit of BSN students according to demographic profile goes almost on same pattern. In an instance that, "exam technique" and "lack of distraction" study habit by the third year BSN student were on same rank on scaling based on their weighted means.

On the other hand, the authors attempted to validate if there are differences on learning style and study habit of the BSN students as per their demographic profile. In regards to the learning style of the BSN students, It was found that there is a significant differences according to year level at $p<.05$ level with $[F(3,8)=74.776, p=.000]$. This means that the learning style of BSN students differ from one year level to another in which it is obviously shown in Table 1 . As to age group, the result confirms that the means of 2 variables do not vary too much at which the variability of the two groups is not significantly different. The finding is opposite with the result of a study conducted in the faculty of languages in the University of Tripoli, Libya that there is a significant difference between learning style of Libyan college students according to age group at which, in every year that their age increases, their learning style changes from one to another. ${ }^{[36]}$ Moreover, gender is one of the factors that affect learning style. However, generalizations regarding male and female learning styles are difficult to state due to conflicts in published evidences. This study revealed that there is no significant difference between the male students $(\mathrm{M}=7.27$, $S D=1.14)$ and female students $(\mathrm{M}=6.68, S D=1.05)$ with $[t(4)=0.933, p=.544]$. In support to our finding, a study, examined learning styles among first-year medical students to determine if there was a difference in learning style preferences in terms of gender. The researchers noted that there was no significant difference according to gender. ${ }^{[37]}$ Furthermore, a study conducted that investigated the individual learning of Southeast Asian students indicates no significant difference between Asian and American students' learning style preferences in terms of gender ${ }^{[38]}$ same as to a study 
conducted whose focus is on Hispanic university students at which the Barsch learning inventory was administered to 137 nursing students and the study showed that there were no significant differences between male and female nursing students. ${ }^{[39]}$ In addition, another study showed no significant difference between the learning style preferences of male and female nursing students using VARK learning styles questionnaire. ${ }^{[40]}$ Similar study also reported no significant differences in learning style preferences on the basis of gender among undergraduate students in AUE. ${ }^{[41]}$ In contrary, a study that examined general surgery residents at the University of Cincinnati during the period of 1994 to 2006 and the result reported significant differences in learning styles between male and female general surgery residents. ${ }^{[42]}$ Another study with contradicting result was conducted to investigate gender differences among learning styles of 1,637 adolescents from Bermuda, Brunei, Hungary, Sweden and New Zealand. The results highlighted a significant difference for gender in general and interaction by countrie ${ }^{[43]}$ and a study reported that there is significant difference in learning styles among male and female students when they used a Gregorc style delineator to evaluate the effect of gender on learning styles within secondary school students in Hong Kong. ${ }^{[44]}$ Furthermore, confirmation on differences with regard to the study habit of the BSN students according to their demographic profile shows that there is no statistically significant difference between the study habit of BSN students according to year level at which the differences between means are likely due to chance and not likely due to what level in nursing curriculum a student enrolled in. This is maybe because of the effect or influence the kind they usually do as their study habit in the lower years of their studies. Moreover, there is no significant difference between the age group of 17-19 $(\mathrm{M}=6.04, S D=1.76)$ and age group 20-23 $(\mathrm{M}=6.10$, $S D=1.92)$ regarding their study habit scale $[t(6)=0.048$, $p=.963]$ while there is no significant difference between the male students $(\mathrm{M}=5.95, S D=1.68)$ and female students $(\mathrm{M}=6.26, S D=1.77)$ regarding their study habit $[t(6)=0.248, p=.812]$ which is similar to the study of Gudaganavar and Halayannavar ${ }^{[45]}$ though it is not on the significant difference in which they validated that there was no association between boys and girls on study habits.Another study revealed that significant difference exists in the study habits of students in relation to gender ${ }^{[46]}$ which is in contrary with the result of this study. It was also the aim of this endeavor to validate if the learning style of the BSN students is correlated with their study habit. The authors utilized the PPMCC test at which the correlation between learning style and study habit is significant at the 0.01 level (2-tailed). This means that there is a strong relationship between the learning style and study habit of BSN students in Al Jabal Al Gharbi University in Gharyan, Libya. The finding is similar to a study conducted ${ }^{[47]}$ that significant relationships between learning styles, study habits, and learning performances were revealed. Another study that coincide with our finding ${ }^{[48]}$ that the result showed learning styles were found to be significantly correlated to study habits at which learning style is important predictors of a study habit.

\section{Conclusions}

Education is vital as it nurture and cultivate mentality of an individual. Through proper learning, an individual be educated but no matter how interested an individual be learned, it can never be achieved unless learning style be established. Yet, education cannot be completely attained without a study habit that fits to learner's how to learn that learning style and study habit goes together not only in learning but also help an instructor to support students individually leading to successful teaching. ${ }^{[49]}$ With this and through the statistical treatment that was carried and the findings made on the learning style and study habit of BSN students of $\mathrm{Al}$ Jabal Al Gharbi University, Gharyan, Libya, the following conclusions were made:

(1) There are 148 (81.32\%) available who participated in this study at which first year BSN students outnumbered in the total sample while fourth year students were the least. Most of them are at the teenage stage (17-19 years old) and are females.

(2) Generally, BSN students are visual learners. Considering their demographic profile, first year BSN students are kinesthetic learners while the second, third and fourth years are all visual same as with the age group and gender of the respondents.

(3) Motivation was the most scaled study habits of the BSN students in general same as through with their demographic profile.

(4) There is a significant difference on learning style of BSN students according to year level while there were no significant differences on learning style according to age group and gender of the respondents.

(5) There is no statistically significant difference between the study habit of BSN students according to year level while there are no significant differences according to age groups and gender.

(6) The correlation of learning style and study habit of the BSN students of Al Jabal Al Gharbi University is significant. 


\section{REFERENCES}

[1] Afful-Broni A, Mawusi H. Study habits as ppredictors of academic performance: a case study of students at Zoin Girls Senior High School, Winneba, Ghana. Global Journal of Educational Research. 2010; 9(1-2): 57-63. http://dx.doi.org/10.4314/gjedr.v9i $1-2.62525$

[2] Hogan TP, Hendrickson E. The study habits of adult college students (a project funded by The Metropolitan Life Foundation), University of Wisconsin-Green Bay, Wisconsin 54301-7001. 1983.

[3] Vazquez FM. Learning and study habits of United Arab Emirates students. (Doctoral dissertation). Pennsylvania State University, USA; 2000 .

[4] Azikiwe U. Study approaches of university students. WCCI Region II Forum. 1998; 2: 106-114.

[5] Chaudhry AH. Effect of guidance services on study attitudes, study habits and academic achievement of secondary school students. Bulletin of Education and Research. 2006; 28(1): 35-45.

[6] Garcia E. Supplemental instruction, study habits, and the community college student. (Doctoral dissertation). Florida International University, USA; 2006.

[7] Igun SE, Adogbeji OB. Study Habits of Postgraduate Students in Selected Nigerian Universities. Abraka, Nigeria, Library Philosophy and Practice. 2007. PMid: 18080587.

[8] Crede M, Kuncel N. Study habits meta-analysis. Perspectives on Psychological Science in Press. 2008; 3(6): 425-453. PMid: 26158971.

[9] Schmid S, Yeung A, Read J. Students' Learning Styles and Academic Performance. In M. Gupta-Bhowon, S. Jhaumeer-Laulloo, H. L. K. Wah \& P. Ramasami (Eds.), Chemistry Education in the ICT Age (pp. 249-262): Springer Netherlands. 2009. http: //dx.doi.org/10.1007/978-1-4020-9732-4_23

[10] Bailey PD, Garratt J. Chemical education: theory and practice. University Chemistry Education. 2002; 6: 39-57. Available from: http: //www.rsc.org/pdf/uchemed/papers/2002/p8_bailey.pdf

[11] Smith PJ, Dalton J. Getting to grips with learning styles. 2005. Available from: http://johnwatsonsite.com/Share-Eng/SIC/G etting_to_grips_with_learnng_styles.pdf

[12] Felder RM, Silverman LK. Learning and teaching styles in engineering education. Engineering education. 1988; 78(7): 674-681. Available from: http://www4.ncsu.edu/unity/lockers/user s/f/felder/public/Papers/LS-1988.pdf

[13] Kolb DA. Experiential learning: Experience as The Source of Learning and Development. New Jersey: Prentice-Hall; 1984.

[14] Dunn R, Honigsfeld A, Doolan LS, et al. Impact of learning-style instructional strategies on students' achievement and attitudes: perceptions of educators in diverse institutions. A Journal of Educational Strategies, Issues and Ideas. 2009; 82(3): 135-140. http: //dx.doi.org/10.3200/tchs.82.3.135-140

[15] Boström L, Lassen LM. Unraveling learning, learning styles, learning strategies and meta-cognition. Education Training. 2006; 48(2/3): 178-189. http://dx.doi.org/10.1108/00400910610651809

[16] Burke K, Dunn Rita. Learning style-based teaching to raise minority student test scores - there's no debate. Clearing House. 2002; 76(2): 103-106. http://dx.doi.org/10.1080/00098650209604959

[17] Kolb DA. Learning Style Inventory, Version 3. Boston, MA: Hay Group, Hay Resources Direct; 1999.

[18] Sadia B. A study of the factors affecting the performance of the students in Government Secondary Schools for girls in Rawalpindi city. M.A. Edu. Thesis. Faculty of Education, International Islamic University, Islamabad; 2005.

[19] Khurshid DF, Tanveer A, Qasmi FN. Relationship between Study Habits and Academic Achievementamong Hostel Living and Day Scholars' University Students. British Journal of Humanities and Social Sciences. 2012; 3(2): 34-42. Available from: http://www.ajournal.co.uk/HSpdfs/HSvolume3 $\% 28$ $2 \% 29 / \mathrm{HSVol}, 3 \% 20 \% 282 \% 29 \% 20$ Article $\% 204$.pdf

[20] Hoeffner KA. The effects of learning-styles information on the achievement of community collegedevelopmental math students. University of South Florida. 2010.

[21] Fielden K. Evaluating Critical Reflection for Postgraduate Students in computing.I nforming Science and Information Technology Education Joint Conference. 2005. Available from: http: //www . info rmingscience.org

[22] Nneji L. Study Habits of Nigerian University Students. HERDSA conference. 2002. Available from: http://www. ecu.edu . au

[23] Gettinger M, Seibert JK. Contributions of study skills to academic competence. School Psychology Review. 2002; 31(3): 350-365. Available from: http://www.wce.wwu.edu/Depts/SPED/For $\mathrm{ms} /$ Kens $\% 20$ Readings/Instruction/Instruct $\% 20$ Contribu tions $\% 20$ of $\% 20$ study $\% 20$ skills $\% 20$ Gettinger $\% 202002$.pdf

[24] Rana SA, Kausar R. Comparison of Study Habits and Academic Performance of Pakistani British and WhiteBritish Students. Pakistan Journal of Social and Clinical Psychology. 2011; 9: 21-26. Available from: http://www.gcu.edu.pk/FullTextJour/PJSC $\mathrm{S} / 2011 / 4 \cdot \mathrm{pdf}$

[25] Leacock C, Warrican S, Rose G. Research methods for inexperienced researchers. Kingston Jamaica: Ian Randle Publishers; 2009.

[26] Barbe WB, Swassing RH, Milone Michael N. Teaching through modality strengths: concepts and practices. Columbus, Ohio: ZanerBloser; 1979.

[27] Barbe WB, Milone MN. What we know about modality strengths. Educational Leadership (Association for Supervision and Curriculum Development). 1981; 378-380.

[28] Learning Styles Inventory. Academic Success Services, Teaching And Learning Center, 7688. Available from: https://www.puc.edu/__data/assets/pdf_file/000 3/13395/Learning-Styles-Inventory.pdf

[29] Entwistle NJ, Brennan T. The academic performance of students British Journal of Educational Psychology. 1971; 41(41): 268276. http://dx.doi.org/10.1111/j.2044-8279.1971.tb0 $0671 . x$

[30] Dunn R, Dunn K. Teaching Students through their Individual Learning Styles. A Practical Approach. Prentice Hall, Reston, VA.; 1978.

[31] Reid JM. The learning style preferences of ESL students. TESOL Quarterly. 1987; 21(1): 87-111. http://dx.doi.org/10.2307/3 586356

[32] Melton CD. Bridging the cultural gap: a study of Chinese students' learning style preferences. RELC Journal. 1990; 21(1): 29-54. http://dx.doi.org/10.1177/003368829002100103

[33] Jones NB. Applying learning styles research to improve writing instruction. Paper presented at RELC Seminar on Learners and Language Learning, Singapore. 1997.

[34] Rossi-Le L. Learning styles and strategies in adult immigrant ESL students. In J.M. Reid ed.), Learning styles in the ESL/EFL classroom. Boston: Heinleand Heinle; 1995. 119-25. Available from: rtlets/recordDetails/detailmini.jsp?_nfpb=true \&_\&ERICExtSearch_SearchValue_0=EJ372622\&ERIC

[35] Hyland K. Culture and learning: a study of the learning style preferences of Japanese students. RELC Journal. 1993; 24(2): 69-91. http://dx.doi.org/10.1177/003368829302400204

[36] Kibasan J II A, Singson EC. Culture and Education: A study on Learning Style of Libyan College Students in Tripoli, Libya. Journal of Education. 2016, 6(1): 17-24. 
[37] Slater J, Lujan L, DiCarlo S. Does gender influence learning style preferences of first - year medical students. Advance in Physiology Education. 2007; 31: 336-342. http://dx.doi.org/10.1152/a dvan.00010.2007

[38] Park C. Learning style preferences of Southeast Asian students. Urban Education. 2000; 35: 245-268. http://dx.doi.org/10.11 $77 / 0042085900353002$

[39] Sizemore M, Schultz P. Ethnicity and gender influences on learning styles in nursing students from an Hispanic-Serving Institution. Journal of Hispanic Higher Education. 2005; 4(4): 343-353. http://dx.doi.org/10.1177/1538192705279590

[40] Alkhasawneh IM, Mrayyan MT, Docherty C, et al. Problem-Based Learning (PBL): Assessing Students' Learning Preferences Using Vark. Nurse Education Today. 2008; 28(5): 572-579.

[41] Paul S, Bojanczyk M, Lanphear JH. Learning preferences of medical students. Medical Education. 1994; 28(3): 180-186.

[42] Mammen J, Fuscher D, Anderson A, et al. Learning styles vary among general surgery residents: amalysis of 12 years of data. Journal of Surgical Education. 2007; 6(6): 386-389. http://dx.doi.o $\mathrm{rg} / 10.1016 / \mathrm{j} \cdot \mathrm{j}$ surg . 2007.08.005

[43] Honigsfeld A, Dunn R. High school male and female learning style similarities and differences in diverse nations. The Journal of Educational Research. 2003; 96(4): 195-206. http://dx .doi .org/1 $0.1080 / 00220670309598809$
[44] Lau W, Yuen A. Promoting conceptual change of learning sorting algorithm through the diagnosis of mental models: the effect of gender and learning styles. Computers \& Education. 2010; 54(1): 275-288.

[45] Nagaraj VG, Rajashekhar BH. Influence of Study Habits on Academic Performance of Higher Primary School Students, International Journal of Science and Research (IJSR), ISSN (Online): 2319-7064. 2014; 3(2): 277-80. Available from: http://www.ijsr.net/arc hive/v3i2/MDIwMTM5Mzg\%3D.pdf

[46] Razia B. Study habits of secondary school students in relation to their socio-economic status and gender, Int. J. Soc. Sci. Manage. 2015 ; 2(1): 68-73. Available from: www.ijssm.org/\&http: //nepjol.info/index.php/IJSSM/issue/archive

[47] Çakiroglu Ü. Analyzing the effect of learning styles and study habits of distance learners on learning performances: a case of an introductory programming course. International Review of Research in Open \& Distance Learning. 2014; 15(4): 161-185.

[48] Sabahattin D Analysis of Study Habits and Learning Styles in University Students. Kastamonu Education Journal. 2013; 21(1).

[49] Tseng CR, Chu HC, Hwang GJ, et al. Development of an adaptive learning system with two sources of personalization information. Computers \& Education. 2008; 51(2): 776-786. http: //dx.doi.org/10.1016/j.compedu. 2007.08.002 